\title{
Markers of subsyndromal depression in very old persons.
}

\author{
Mikael Ludvigsson, Jan Marcusson, Ewa Wressle and Anna Milberg
}

\section{Linköping University Post Print}

\section{Tweet}

N.B.: When citing this work, cite the original article.

Original Publication:

Mikael Ludvigsson, Jan Marcusson, Ewa Wressle and Anna Milberg, Markers of subsyndromal depression in very old persons., 2016, International Journal of Geriatric Psychiatry, (31), 6, 619-628.

http://dx.doi.org/10.1002/gps.4369

Copyright: Wiley: 12 months

http://eu.wiley.com/WileyCDA/

Postprint available at: Linköping University Electronic Press

http://urn.kb.se/resolve?urn=urn:nbn:se:liu:diva-127480 


\section{Markers of subsyndromal depression in very old persons}

\section{Authors:}

1. Mikael Ludvigsson, MD, PhD Student. Division of Geriatric Medicine, Department of Clinical and Experimental Medicine, Linköping University, Linköping, Sweden. Department of Psychiatry, County Council of Östergötland, Sweden.

2. Jan Marcusson, MD, PhD. Division of Geriatric Medicine, Department of Clinical and Experimental Medicine, Linköping University, Linköping, Sweden. Department of Geriatrics, County Council of Östergötland, Sweden.

3. Ewa Wressle, PhD. Division of Geriatric Medicine, Department of Clinical and Experimental Medicine, Linköping University, Linköping, Sweden. Department of Geriatrics, County Council of Östergötland, Sweden.

4. Anna Milberg, MD, PhD. Department of Social and Welfare Studies, Linköping University, Norrköping, Sweden. LAH/Unit of Palliative Care, County Council of Östergötland, and Palliative Education and Research Centre in the County of Östergötland, Sweden.

\section{Address correspondence to Mikael Ludvigsson:}

- Psykosmottagningen, Psykiatriska kliniken, Universitetssjukhuset, 58185 Linköping, Sweden.

- E-mail: mikael.ludvigsson@regionostergotland.se

- Telephone no: $+46-76-8438473$.

- Fax no: can be offered on request.

Sponsors: This work was supported by grants from the County Council of Östergötland, Sweden.

Word count of body text: 3731 .

Potential conflict of interest: None to declare. 


\section{Introduction}

In old or very old people, it can be hard to distinguish between depression, subsyndromal depressive states and normal aging (Alexopoulos et al., 2008, Fiske et al., 2009, Ludvigsson et al., 2014). Because of this, and because of the varying definitions of different depressive states, the figures for the prevalence of syndromal and subsyndromal depression (SSD) vary between different studies (Rodriguez et al., 2012). Inattention to the diagnosis of depression has been described as a widespread problem, and as the subsyndromal or subthreshold depressive states are less prominent in the clinical meeting, the risk of under-diagnosis is even greater than for syndromal depression (Alexopoulos and Kelly, 2009).

Nevertheless, subsyndromal depression is common and is associated with suffering, functional decline, poor prognosis, as well as increased medical costs for society (Meeks et al., 2011, Lyness et al., 2007, Laborde-Lahoz et al., 2014). Additional arguments for identifying subsyndromal depression are that treatment and prevention seem to have positive effects, and that research on mood disorders needs to include subsyndromal states in order to capture a broader panorama of mood conditions (Moss et al., 2012, Cuijpers et al., 2007, Insel, 2009). The importance of this has over the last years, been particularly emphasized by the fact that patients with major depressive disorder present only subsyndromal depression in certain periods of the long-term course, and this corresponds well to a dimensional view of mood disorders in the DSM-5 (Judd, 2012, American Psychiatric Association, 2013).

According to a recent review of subthreshold depression, some risk factors seem well established while others remain to be identified in order to guide effective prevention efforts (Meeks et al., 2011). For example, past history of affective disorder, visual or 
cognitive impairment and female gender are known risk factors, and decreased social support, lower education, medical burden and disability also have a well-established association with SSD even though the directionality of the causalities are less sure (Meeks et al., 2011).

However, most of these studies on older adults include samples in which "older adults" means young old (65-80 years of age), and there are only few studies on SSD in the very old or the oldest old (>80 years)(Meeks et al., 2011). Certain aspects of life change between the young old and the very old ages, and these contribute to the distinction between the third and the fourth ages of life. The fourth age is characterized by frailty, cognitive decline and functional loss, while the younger persons of the third age still have independence, social engagement and good health (Baltes and Smith, 2003). As demographic development worldwide indicates a gradual increase in the proportion of very old persons, it seems urgent to deepen our understanding of this group.

One could argue that studies on persons in long-term-care correspond to research in this fourth age even in slightly younger chronological ages (Jongenelis et al., 2004, Lee et al., 2013), but to our knowledge there are few studies in community settings focusing on SSD in the very old (Paivarinta et al., 1999, Geiselmann et al., 2001). The present study is a population-based survey on all 85-year-old persons in the community of Linköping, Sweden. The aims of this study were to investigate factors associated with SSD in very old persons, and to develop a model for prediction of SSD among very old persons.

Based on previous literature, we hypothesized that SSD in very old persons would be related to sociodemographic characteristics (e.g. female gender, lower education), declining physical functioning (e.g. problems with mobility), or neuropsychiatric factors (e.g. history of 
affective psychiatric disorder, cognitive dysfunctioning). We also hypothesized that existential factors (e.g. lack of meaningfulness in life) would be associated with SSD in very old persons, because such aspects have previously been reported to be associated with syndromal depression (Hedberg et al., 2011).

\section{Methods}

This study is part of the Elderly in Linköping Screening Assessment (ELSA 85), a larger research project with a population-based design (85-year-old persons in the south of Sweden) with the aim of acquiring evidence-based knowledge on how best to plan, design and provide health care for the oldest-old (Nagga et al., 2012). The present study was approved by the Research Ethics Committee of Linköping University, Sweden (141-06). Written informed consent was obtained from all participants and they were told that participation was voluntary and confidential.

\section{Participants and Procedure}

All persons born in 1922 and living in Linköping municipality in Sweden ( $n=650)$ received, in 2007, a postal questionnaire and a covering letter. The letter contained information about the study and options for participation in each phase of the study, and made it clear that participation in the study was voluntary. A flow diagram explaining the derivation of the analytical samples used in the analyses is given in Figure 1. Of the eligible individuals, $76 \%$ $(496 / 650)$ provided written informed consent and answered the postal questionnaire. The next phase included a home visit by an occupational therapist, who interviewed the 380 remaining participants (77\% of 496$)$ and performed assessments that included use of the depression screening instrument GDS-15 (Sheikh and Yeasavage, 1986). This phase also 
involved a subsequent reception visit where a medical doctor in connection with a medical examination asked some extra questions. Approximately 4 weeks elapsed between the postal questionnaire, the home visit, and the reception visit altogether. In a few cases a caregiver instead of the subject filled in the initial postal questionnaire, but for the interview of the GDS-15 questions all subjects were able to respond for themselves, in spite of for example cognitive or hearing impairments. With an internal drop-out of nine cases, 371 individuals answered the GDS-15 questions, and their responses were used for the analyses in this study.

[Place for Figure 1]

\section{Measures}

Measurement of outcome: The dependent variables were three categories of depressiveness: non-depression (ND), SSD and syndromal depression. Definitions of SSD vary in the literature (Meeks et al., 2011). In some studies, a definition has been made on the basis of results from a screening instrument (Lyness et al., 2007, Jongenelis et al., 2004, Hybels et al., 2009). In this study, we chose to define SSD and syndromal depression on the basis of the results from GDS-15 (Sheikh and Yeasavage, 1986). GDS-15 is a valid and reliable self-report screening instrument assessing depressive symptoms in older people, and it contains of 15 questions with yes/no-answers and one point for each question(de Craen et al., 2003). In our study $0-2 p$ were interpreted as ND, 3-5p were interpreted as SSD, and $>5 p$ were interpreted as syndromal depression. Thus the definition of SSD and syndromal depression in this study is not completely equivalent to diagnostic classification registries. Some studies use the cut-off of 4/5p from GDS-15 to detect depression in screening (de Craen et al., 2003), but for our purposes we required a higher specificity for identifying those 
with syndromal depression, and therefore chose the higher cut-off of 5/6p (Chachamovich et al., 2008).

Sociodemographic factors: The postal questionnaire included questions about gender, housing, education and contact with neighbours. These questions were constructed by the authors and most were on a yes/no scale, except for the one about contact with neighbours, which was arranged on a three-level scale of close, some, or no contact.

Declining physical functioning: The postal questionnaire included questions about mobility assistive devices and visual impairment, on a yes/no scale. At the home visit the EQ-5D (Rabin and de Charro, 2001, EuroQol, 1990) was used. This is a generic instrument that assesses health-related quality of life in terms of an EQ visual analogue scale (EQ VAS) and a descriptive system of the five dimensions of usual activities, self-care, mobility, pain/discomfort, and anxiety/depression. Each of the five dimensions is evaluated using three levels: no problems, some problems, and severe problems. At the reception visit additional questions were asked about heart failure and myocardial infarction, using a yes/no scale.

Neuropsychiatric factors: The postal questionnaire included open-ended questions about current and previous diseases and on-going medications. To secure the validity of the patient-reported psychiatric morbidity, the physicians were encouraged to pose follow-up questions in connection with a clinical examination, and the morbidity were categorized as history of affective disorder, history of anxiety disorder, use of tranquilizing medication, and history of stroke, using a yes/no scale. Overall cognitive function was assessed the home visit using the MMSE (Folstein et al., 1975, Crum et al., 1993), and results $<25 p$ of the 
maximum 30p were regarded as cognitive dysfunction in this study (Iverson, 1998).

Executive cognitive function was assessed using the Victoria Stroop test, and results $>70$ seconds on the Color Word Time scores were regarded as executive dysfunction, approximately corresponding to -1SD in normative data for the age group (Troyer et al., 2006). The EQ-5D dimension anxiety/depression above was included in this neuropsychiatric domain of factors.

Existential factors: The postal questionnaire included author-constructed questions about feelings of loneliness and worries about the future, on a four-level scales of frequency: often, sometimes, seldom or never. Self-perceived health was assessed using the EQ VAS, also in the EQ-5D (Rabin and de Charro, 2001, EuroQol, 1990), which records the respondent's self-perceived health on a vertical, visual analogue scale in which the endpoints are labelled 'best imaginable health state' (100) and 'worst imaginable health state' (0). Results less than median value 70 out of maximum 100 were considered as lower self-perceived health, with an overall distribution of EQ VAS results approximately the same as for non-institutionalized elderly persons (Leon-Salas et al., 2014). Self-perceived meaningfulness of life was assessed at the reception visit using an author-constructed fivelevel question with the response alternatives 'yes highly meaningful', 'yes rather meaningful', 'neither meaningful or not', 'not really meaningful', or 'lack of meaningfulness'.

\section{Statistical Analyses}

Comparisons with $X^{2}$-test between those who responded to GDS $(n=371)$ with those who responded to the postal questionnaire but not to GDS or further measurements ( $n=125)$ revealed that a significantly larger proportion of non-responders were of female gender, living in adapted housing, had problems with mobility, usual activities, self-care and selfperceived health according to the EQ-5D-items. The non-responders on the other hand had 
significantly less visual impairment, history of stroke and history of heart failure or myocardial infarction compared to the responders.

The numbers of missing values among the participants were generally small, ranging from 0 to $7.3 \%$ (27/371 on the question concerning self-perceived meaningfulness). Descriptive statistics were calculated for the individual variables, with frequencies and percentages for categorical data. Correlation matrices were calculated to identify significant intercorrelation between explaining variables, and three variables were excluded for this reason. Multicolinearity was controlled for by correlation analyses including calculations of the Variance Inflation Factor (VIF). For the subsequent logistic regressions all independent variables were dichotomized, which was done according to the cut-off values above, according to yes/no responses, and dichotomization of ordinal response alternatives according to table 1.

Univariate logistic regression was used to calculate odds ratio (OR) estimates and $95 \%$ confidence intervals $(\mathrm{Cl})$. All variables with significant associations in the univariate logistic regressions were included in the following multivariate binary logistic regressions, using algorithms for automatic model selection to select measures independently associated with each outcome relation (ND-SSD, SSD-syndromal depression and ND-Syndromal depression, respectively).

Finally, in order to develop models for prediction of SSD among very old persons according to both a dimensional perspective on depressiveness and a categorical perspective, different types of multivariate regressions were performed, namely linear regression (continuous perspective), ordinal logistic regression (continuous perspective) and a binary logistic 
regression (categorical perspective) (American Psychiatric Association, 2013, Judd, 2012). A conceptual overview of the two perspectives on depressiveness is depicted in Figure 2. In the linear and the ordinal logistic regressions, the same independent variables were included as in the previous multivariate binary logistic regressions, and regression coefficients (B), odds ratio $(\mathrm{OR})$ estimates and $95 \%$ confidence intervals $(\mathrm{Cl})$ were calculated. A linear regression model with the GDS score as outcome variable is closer to the concept of the continuous perspective, while the alternative ordinal logistic model (with the outcome categories ND-SSD-Syndromal depression) is further away from the concept but can be regarded more appropriate as the GDS-15-scale in fact is ordinal. Another reason for choosing ordinal logistic regression as an alternative to linear regression is that comparability with results from the binary logistic calculations increases. The regression models were not corrected for multiple comparisons, though the results were interpreted with caution. The statistical software SPSS version 21.0 was used in all analyses, and differences were deemed significant if the $P$ value was less than 0.05 .

[Place for figure 2]

\section{Results}

\section{Sample Characteristics}

Ninety-nine (27\%) of the 371 participants were classified as having subsyndromal depression (SSD), 23 (6\%) as having syndromal depression and 249 (67\%) as having non-depression (ND). Anti-depressive medication was used by 21 (22\%) of persons with SSD, four (17\%) of those with syndromal depression and $12(5 \%)$ of those with non-depression. The characteristics of the 371 participants are presented in Table 1. 


\section{Analysis of Individual Variables}

The univariate logistic regression analyses revealed 20 independent variables that had significant associations with the dependent variables, i.e. the three categories of depressiveness (ND, SSD and syndromal depression respectively), also shown in Table 1.

[Place for Table 1]

\section{Model building}

The variables that had significant associations with the outcome variables were used for model building through multivariate binary stepwise logistic regression analyses (the results shown in table 2). For the likelihood of participants being SSD instead of ND seven independent factors were found that significantly contributed to a final model. Here, these are presented in descending order of odds ratios: lower self-perceived health (EQ VAS), life not meaningful, problems with self-care, no contact with neighbours, use of tranquilizing medication, personal history of affective disorder, and history of stroke. Two factors that significantly increased the likelihood for participants of having syndromal depression instead of SSD were identified through multivariate logistic regression: not meaningful life and higher actual Anxiety/Depression.

Then, an ordinal logistic regression and a linear regression was performed in order to investigate the relations across the whole spectrum of depressive categories, more in line with a modern dimensional perspective on depressive disorders (the results are shown in table 2). The ordinal logistic regression seemed to fit the data (as the test of parallel lines was not significant), and through these analyses seven factors turned out to significantly contribute to a final model. These factors were the following, here presented in descending order of odds ratios: life not meaningful, lower self-perceived health, no contact with 
neighbours, use of tranquilizing medication, problems with usual activities, personal history of stroke, worries about the future. In the linear regression the same seven factors were significantly associated to the outcome GDS score.

[Place for Table 2]

\section{Discussion}

This population-based study has identified 20 factors associated with subsyndromal depression in very old persons, and all the hypothesized domains - sociodemographic factors, declining physical functioning, neuropsychiatric factors, and existential factors significantly related to SSD in this population of very old persons. The results regarding low education, visual impairment and history of heart failure or myocardial infarction contrast with previous studies. Possibly this different pattern of markers for SSD might be a reflection of the greater age of the participants in this study, since longstanding vulnerability factors might decline in importance as the most vulnerable elderly selectively leave the population, while on the other hand, life condition factors of the fourth age with declining physical functions and increasing degrees of dependence assume greater importance. Similar thoughts have been suggested previously in the context of syndromal depression (Vink et al., 2008).

In addition to the univariate regressions we also implemented multivariate binary, ordinal logistic and linear regression models for predicting SSD in the very old, shown in table 2. Overall, this study replicates many earlier findings ((Meeks et al. (2011)), but extends also our knowledge of SSD in very old persons. 


\section{Predictive models of SSD in very old persons}

More generally, the multivariate logistic, ordinal logistic and linear regression models developed in this study contribute to the pursuit of better prediction of both subsyndromal depression and overall depressiveness in very old persons. The multivariate logistic model included seven independent factors that increase the likelihood of SSD instead of ND, which means that awareness of these factors when meeting a very old patient in the community or at the health centre can increase the odds of detecting subsyndromal depression. The ordinal logistic and the linear regression models resulted in seven partly different factors that similarly can improve detection of depressiveness (SSD or syndromal depression) more generally.

From a methodological perspective, our multivariate binary, ordinal logistic and linear regression models raise the question of the relevance of thresholds in psychiatric medical care. The ordinal logistic and linear regression models support an increasingly prevalent perception in psychiatry that the difference between depression and normal aging is a matter of degree on a continuum, from healthy or successful aging at one end to severe depression at the other end (Judd, 2012). Our multivariate binary models on the other hand, with partly different relationships between ND and SSD on one hand and between SSD and syndromal depression on the other hand, remind us that there might be certain factors that differ categorically between healthy aging and degrees of depressiveness (Ayuso-Mateos et al., 2010), at least in the very old population. In the present study, the factors of selfperceived problems of self-care and actual anxiety/depression were not significantly associated with the outcome in the ordinal logistic or linear regressions but only in the multivariate binary regression, which indicates categorical differences, while other factors 
differed continuously with significance both in multivariate binary, ordinal logistic and linear regressions. Thus, one possible conclusion would be that some aspects of ND, SSD and syndromal depression in very old persons may differ categorically, while other aspects may differ continuously more according to a dimensional view on depressive disorders. Similar thoughts have been presented in earlier articles, though the empirical basis has varied (Ayuso-Mateos et al., 2010, Lee et al., 2013, Judd, 2012).

\section{Markers of SSD in the doctor's meeting with the very old patient}

Sometimes the geropsychiatric patient describes the personal situation in other words or signs than the classical psychiatric terminology for depressive episodes. This is important because in addition to awareness of atypical symptoms, we need, according to the findings of this study, to pay attention also to these other markers of depressiveness in the very old. More visible markers might include an x-ray showing cerebrovascular lesions, or signs of problems with mobility, while less visible markers may include factors such as feelings of Ioneliness, worries about future living conditions, restricted subjective health, or lower meaningfulness.

The concept of meaningfulness has been described as a link in a chain from religiousness to well-being (Frankl, 1963, Lambert et al., 2013), and in the context of the fourth age the individual generally goes through a life crisis with a possible reorientation of values as the life conditions change, described for example in the theories of Selective Optimization with Compensation (SOC-model) and Strength and Vulnerability Integration theory (SAVI) (Charles, 2010). Accompanying the declining physical functions is a risk of losing sources of meaningfulness and instead having reasons to worry about the future, but the individual may handle this crisis in various ways, for example by the strategy of selecting new values in life that give new sources of meaningfulness. 
Due to these less visible markers of SSD in the very old persons, it might be a challenge for a medical doctor alone to identify and treat depressiveness in people of these ages. For example, it may be hard to decide which functional disability is relevant, and to design the appropriate treatment, although such tasks may be facilitated by collaboration with other occupational categories of the team, as for example with an occupational therapist. In addition, by asking or even just paying attention to existential aspects in the clinical meeting with the very old patient, there is a chance of identifying depressiveness and also promoting relevant coping strategies that will be used by the medical doctor or by other colleagues in a primary care or a geropsychiatric team.

A possible bonus from the extra attention to these kinds of off-road markers of depressiveness in the meeting with the geropsychiatric patient is that this attention also, in a natural way, leads the conversation to a more comprehensive functional approach to treatment. The comprehensive geriatric or functional approach to treatment means using not only pharmacological device but also different kinds of psychosocial interventions with psychiatric disorders, something that has often been neglected in geriatric psychiatry (Blazer, 2000).

\section{Limitations}

A few limitations of this study should be considered. First, there was a relatively large loss of participants in this population-based survey, partly due to the study design since inclusion in this study was the second stage of a more comprehensive study. This fact, and the fact that there were differences between the responders to GDS and the non-responders, may have consequences for the generalizability of the results for women, for persons living in sheltered housing, and for those having lower self-perceived health or problems with mobility, self-care or usual activities. 
Second, the outcome variables of SSD and syndromal depression were defined by a selfreport depression screening instrument, and not by using the diagnostic classification system DSM-5 as a gold standard of classification, and this may, as in other similar studies, have consequences for the validity of the study. Also, the statistical power is a limitation for some of the analyses, as the number of participants in two of the study groups was small.

Finally, the study was a cross-sectional one; thus, the observed associations among variables might not be causal. Longitudinal research into the markers and the trajectory of SSD in very old persons would be a valuable addition to the literature and could identify opportunities for intervention.

\section{Conclusion}

In conclusion, we have identified a number of factors associated with subsyndromal depression in very old persons, and we have also, by means of multiple binary logistic, ordinal logistic and linear regressions, developed models for predicting SSD and depressiveness in the very old. This is of importance for detection, prevention and treatment of these depressive states. Our findings indicate the importance of a comprehensive functional approach to diagnosing and treating depressiveness in very old persons, and the findings might also be interpreted as providing support for the coexistence of both a dimensional and a categorical view on depressive disorders.

ALEXOPOULOS, G. S., GUNNING-DIXON, F. M., LATOUSSAKIS, V., KANELLOPOULOS, D. \& MURPHY, C. F. 2008. Anterior cingulate dysfunction in geriatric depression. Int J Geriatr Psychiatry, 23, 347-55. 
ALEXOPOULOS, G. S. \& KELLY, R. E., JR. 2009. Research advances in geriatric depression. World Psychiatry, 8, 140-9.

AMERICAN PSYCHIATRIC ASSOCIATION. 2013. Diagnostic and statistical manual of mental disorders : $D S M-5$. [Online]. Arlington, $V A$.

AYUSO-MATEOS, J. L., NUEVO, R., VERDES, E., NAIDOO, N. \& CHATTERJI, S. 2010. From depressive symptoms to depressive disorders: the relevance of thresholds. Br J Psychiatry, 196, 365-71.

BALTES, P. B. \& SMITH, J. 2003. New frontiers in the future of aging: from successful aging of the young old to the dilemmas of the fourth age. Gerontology, 49, 123-35.

BLAZER, D. G. 2000. Psychiatry and the oldest old. Am J Psychiatry, 157, 1915-24.

CHACHAMOVICH, E., FLECK, M., LAIDLAW, K. \& POWER, M. 2008. Impact of major depression and subsyndromal symptoms on quality of life and attitudes toward aging in an international sample of older adults. Gerontologist, 48, 593-602.

CHARLES, S. T. 2010. Strength and vulnerability integration: a model of emotional well-being across adulthood. Psychol Bull, 136, 1068-91.

CRUM, R. M., ANTHONY, J. C., BASSETT, S. S. \& FOLSTEIN, M. F. 1993. Population-based norms for the Mini-Mental State Examination by age and educational level. JAMA, 269, 2386-91.

CUIJPERS, P., SMIT, F. \& VAN STRATEN, A. 2007. Psychological treatments of subthreshold depression: a meta-analytic review. Acta Psychiatr Scand, 115, 434-41.

DE CRAEN, A. J., HEEREN, T. J. \& GUSSEKLOO, J. 2003. Accuracy of the 15-item geriatric depression scale (GDS-15) in a community sample of the oldest old. Int J Geriatr Psychiatry, 18, 63-6.

EUROQOL, G. 1990. EuroQol--a new facility for the measurement of health-related quality of life. Health Policy, 16, 199-208.

FISKE, A., WETHERELL, J. L. \& GATZ, M. 2009. Depression in older adults. Annu Rev Clin Psychol, 5, 363-89.

FOLSTEIN, M. F., FOLSTEIN, S. E. \& MCHUGH, P. R. 1975. "Mini-mental state". A practical method for grading the cognitive state of patients for the clinician. J Psychiatr Res, 12, 189-98.

FRANKL, V. E. 1963. Man's search for meaning: An introduction to logotherapy, New York, NY: Washington Square. (Original work published 1946).

GEISELMANN, B., LINDEN, M. \& HELMCHEN, H. 2001. Psychiatrists' diagnoses of subthreshold depression in old age: frequency and correlates. Psychol Med, 31, 51-63.

HEDBERG, P., BRULIN, C., ALEX, L. \& GUSTAFSON, Y. 2011. Purpose in life over a five-year period: a longitudinal study in a very old population. Int Psychogeriatr, 23, 806-13.

HYBELS, C. F., PIEPER, C. F. \& BLAZER, D. G. 2009. The complex relationship between depressive symptoms and functional limitations in community-dwelling older adults: the impact of subthreshold depression. Psychol Med, 39, 1677-88.

INSEL, T. R. 2009. Translating scientific opportunity into public health impact: a strategic plan for research on mental illness. Arch Gen Psychiatry, 66, 128-33.

IVERSON, G. L. 1998. Interpretation of Mini-Mental State Examination scores in community-dwelling elderly and geriatric neuropsychiatry patients. Int J Geriatr Psychiatry, 13, 661-6.

JONGENELIS, K., POT, A. M., EISSES, A. M., BEEKMAN, A. T., KLUITER, H. \& RIBBE, M. W. 2004. Prevalence and risk indicators of depression in elderly nursing home patients: the AGED study. J Affect Disord, 83, 135-42.

JUDD, L. L. 2012. Dimensional paradigm of the long-term course of unipolar major depressive disorder. Depress Anxiety, 29, 167-71.

LABORDE-LAHOZ, P., EL-GABALAWY, R., KINLEY, J., KIRWIN, P. D., SAREEN, J. \& PIETRZAK, R. H. 2014. Subsyndromal depression among older adults in the USA: prevalence, comorbidity, and risk for new-onset psychiatric disorders in late life. Int J Geriatr Psychiatry.

LAMBERT, N. M., STILLMAN, T. F., HICKS, J. A., KAMBLE, S., BAUMEISTER, R. F. \& FINCHAM, F. D. 2013. To belong is to matter: sense of belonging enhances meaning in life. Pers Soc Psychol Bull, 39, 1418-27. 
LEE, M. J., HASCHE, L. K., CHOI, S., PROCTOR, E. K. \& MORROW-HOWELL, N. 2013. Comparison of major depressive disorder and subthreshold depression among older adults in community long-term care. Aging Ment Health, 17, 461-9.

LEON-SALAS, B., AYALA, A., BLAYA-NOVAKOVA, V., AVILA-VILLANUEVA, M., RODRIGUEZ-BLAZQUEZ, C., ROJO-PEREZ, F., FERNANDEZ-MAYORALAS, G., MARTINEZ-MARTIN, P., FORJAZ, M. J., SPANISH RESEARCH GROUP ON QUALITY OF, L. \& AGING 2014. Quality of life across three groups of older adults differing in cognitive status and place of residence. Geriatr Gerontol Int.

LUDVIGSSON, M., MILBERG, A., MARCUSSON, J. \& WRESSLE, E. 2014. Normal Aging or Depression? A Qualitative Study on the Differences Between Subsyndromal Depression and Depression in Very Old People. Gerontologist.

LYNESS, J. M., KIM, J., TANG, W., TU, X., CONWELL, Y., KING, D. A. \& CAINE, E. D. 2007. The clinical significance of subsyndromal depression in older primary care patients. Am J Geriatr Psychiatry, 15, 214-23.

MEEKS, T. W., VAHIA, I. V., LAVRETSKY, H., KULKARNI, G. \& JESTE, D. V. 2011. A tune in "a minor" can "b major": a review of epidemiology, illness course, and public health implications of subthreshold depression in older adults. J Affect Disord, 129, 126-42.

MOSS, K., SCOGIN, F., DI NAPOLI, E. \& PRESNELL, A. 2012. A self-help behavioral activation treatment for geriatric depressive symptoms. Aging Ment Health, 16, 625-35.

NAGGA, K., DONG, H. J., MARCUSSON, J., SKOGLUND, S. O. \& WRESSLE, E. 2012. Health-related factors associated with hospitalization for old people: comparisons of elderly aged 85 in a population cohort study. Arch Gerontol Geriatr, 54, 391-7.

PAIVARINTA, A., VERKKONIEMI, A., NIINISTO, L., KIVELA, S. L. \& SULKAVA, R. 1999. The prevalence and associates of depressive disorders in the oldest-old Finns. Soc Psychiatry Psychiatr Epidemiol, 34, 352-9.

RABIN, R. \& DE CHARRO, F. 2001. EQ-5D: a measure of health status from the EuroQol Group. Ann Med, 33, 337-43.

RODRIGUEZ, M. R., NUEVO, R., CHATTERJI, S. \& AYUSO-MATEOS, J. L. 2012. Definitions and factors associated with subthreshold depressive conditions: a systematic review. BMC Psychiatry, 12, 181.

SHEIKH, J. A. \& YEASAVAGE, J. A. 1986. Geriatric Depression Scale (GDS): recent findings and development of a shorter version. In: BRINK, T. L. (ed.) Clinical Gerontology: A Guide to Assessment and Intervention. New York: Howarth Press.

TROYER, A. K., LEACH, L. \& STRAUSS, E. 2006. Aging and response inhibition: Normative data for the Victoria Stroop Test. Neuropsychol Dev Cogn B Aging Neuropsychol Cogn, 13, 20-35.

VINK, D., AARTSEN, M. J. \& SCHOEVERS, R. A. 2008. Risk factors for anxiety and depression in the elderly: a review. J Affect Disord, 106, 29-44. 
Table 1. Markers of SSD in very old persons $(n=371)$, according to the univariate logistic regression analyses.

\begin{tabular}{|c|c|c|c|c|c|c|c|}
\hline Sociodemographic factors & $\mid \begin{array}{l}\text { ND } \\
(\mathrm{n}=249) \\
\text { No.of subj } \\
\text { (valid percent) }\end{array}$ & $\mid$\begin{tabular}{|l} 
SSD \\
$(\mathrm{n}=99)$ \\
No. of subj \\
(valid percent)
\end{tabular} & $\mid \begin{array}{l}\text { Syndr Depr } \\
(\mathrm{n}=23) \\
\text { No. of subj } \\
\text { (valid percent) }\end{array}$ & \begin{tabular}{|l} 
ND-SSD \\
OR (CI)
\end{tabular} & $\mathrm{p}$ & \begin{tabular}{|l} 
SSD-Depr \\
OR (CI)
\end{tabular} & $\mathrm{p}$ \\
\hline Female gender & $136(54.6)$ & $66(66.7)$ & $16(69.6)$ & $1.66(1.02-2.70)$ & 0.041 & $1.14(0.43-3.05)$ & 0.790 \\
\hline Adapted housing: i.e. sheltered & $9(3.6)$ & $17(17.2)$ & $5(21.7)$ & $5.53(2.37-12.88)$ & $<0.001$ & $1.34(0.44-4.11)$ & 0.609 \\
\hline housing, nursing home or dementia care & & & & & & & \\
\hline Living alone & $138(55.4)$ & 59 (59.6) & $18(78.3)$ & |1.19 (0.74-1.90) & 0.479 & $2.44(0.84-7.11)$ & 0.102 \\
\hline Low education & $168(67.7)$ & $70(70.7)$ & $16(69.6)$ & | $1.15(0.69-1.91)$ & 0.591 & $0.95(0.35-2.54)$ & 0.914 \\
\hline No contact with neighbours & |20 (8.1) & $\mid 16(16.7)$ & $6(26.1)$ & $2.28(1.13-4.61)$ & 0.022 & $1.77(0.60-5.17)$ & 0.300 \\
\hline \multicolumn{8}{|l|}{ Declining physical functioning } \\
\hline Use of mobility assistive devices & $92(36.9)$ & $72(72.7)$ & $19(82.6)$ & $4.55(2.73-7.59)$ & $<0.001$ & $1.78(0.56-5.71)$ & 0.332 \\
\hline Visual impairment & $190(76.3)$ & $82(82.3)$ & $21(91.3)$ & $1.50(0.82-2.73)$ & 0.186 & $2.18(0.47-10.17)$ & 0.323 \\
\hline Usual activities (EQ-5D), some or severe problems & $27(10.8)$ & 45 (45.5) & $15(65.2)$ & $6.85(3.91-12.02)$ & $<0.001$ & $2.25(0.88-5.79)$ & 0.093 \\
\hline Self-Care (EQ-5D), some or severe problems & $12(4.8)$ & $26(26.3)$ & $6(26.1)$ & $7.03(3.38-14.64)$ & $<0.001$ & $0.99(0.35-2.78)$ & 0.986 \\
\hline Mobility (EQ-5D), some or severe problems & $84(34.1)$ & $68(68.7)$ & $18(78.3)$ & $4.23(2.57-6.97)$ & $<0.001$ & $1.64(0.56-4.82)$ & 0.368 \\
\hline Pain/ Discomfort (EQ-5D), moderate or extreme & $140(56.9)$ & $68(69.4)$ & $20(87.0)$ & $2.18(1.28-3.71)$ & 0.004 & $3.18(0.69-14.58)$ & 0.137 \\
\hline History of Heart Failure or Myocardial infarction & $60(24.1)$ & $32(32.3)$ & $4(17.4)$ & $1.50(0.90-2.51)$ & 0.118 & $0.44(0.14-1.40)$ & 0.165 \\
\hline \multicolumn{8}{|l|}{ Neuropsychiatric factors } \\
\hline History of Affective psychiatric disorder & $18(7.2)$ & $20(20.2)$ & $8(34.8)$ & $3.25(1.64-6.45)$ & 0.001 & $2.11(0.78-5.66)$ & 0.140 \\
\hline History of Anxiety disorder & $7(2.8)$ & $11(11.1)$ & $4(17.4)$ & $4.32(1.62-11.50)$ & 0.003 & $1.68(0.48-5.86)$ & 0.413 \\
\hline Actual Anxiety/Depression (EQ-5D), moderate & $57(23.0)$ & $50(50.5)$ & $21(91.3)$ & $3.42(2.09-5.60)$ & $<0.001$ & $10.29(2.29-46.25)$ & 0.002 \\
\hline or extreme & & & & & & & \\
\hline Use of Tranquilizing medication & $8(3.3)$ & $15(15.5)$ & $5(21.7)$ & $5.37(2.20-13.14)$ & $<0.001$ & $1.52(0.49-4.72)$ & 0.470 \\
\hline History of Stroke & $20(8.0)$ & $22(22.2)$ & $6(26.1)$ & $3.27(1.69-6.32)$ & $<0.001$ & $1.24(0.44-3.51)$ & 0.692 \\
\hline Cognitive dysfunction (MMSE) & $27(10.9)$ & $25(25.8)$ & $7(31.8)$ & $2.84(1.55-5.21)$ & 0.001 & $1.34(0.49-3.68)$ & 0.565 \\
\hline Executive dysfunction (Victoria Stroop test) & $58(23.3)$ & $42(42.4)$ & $12(52.2)$ & $2.43(1.48-3.98)$ & $<0.001$ & $1.48(0.60-3.68)$ & 0.398 \\
\hline \multicolumn{8}{|l|}{ Existential factors } \\
\hline Self-perceived loneliness, sometimes or often & $74(29.4)$ & $52(52.5)$ & $20(87.0)$ & $2.62(1.62-4.22)$ & $<0.001$ & $6.03(1.68-21.59)$ & 0.006 \\
\hline Worries about the future, sometimes or often & $3(1.2)$ & $11(11.1)$ & $8(34.8)$ & $3.05(1.88-4.93)$ & $<0.001$ & $4.71(1.31-16.91)$ & 0.017 \\
\hline Lower self-perceived health (EQ VAS) & $63(26.7)$ & $72(75.0)$ & $21(91.3)$ & $8.24(4.78-14.20)$ & $<0.001$ & $3.50(0.76-16.04)$ & 0.107 \\
\hline Life not meaningful & $17(7.3)$ & $25(27.8)$ & $13(65.0)$ & $4.91(2.50-9.65)$ & $<0.001$ & $4.83(1.73-13.50)$ & 0.003 \\
\hline
\end{tabular}


Table 2. Multivariate, and alternative ordinal logistic and linear regression models

\begin{tabular}{|c|c|c|c|c|c|c|c|c|}
\hline \multirow[b]{2}{*}{ Variable } & \multicolumn{2}{|c|}{$\begin{array}{l}\text { Multivariate Log Regr }{ }^{1}, \\
\text { Likelihood of SSD } \\
\text { instead of Non-depr }\end{array}$} & \multicolumn{2}{|c|}{$\begin{array}{l}\text { Multivariate Log Regr }{ }^{2}, \\
\text { Likelihood of Syndr depr } \\
\text { instead of SSD }\end{array}$} & \multicolumn{2}{|l|}{\begin{tabular}{|l} 
Ordinal Log Regr ${ }^{3}$, \\
including Non-depr, \\
SSD and Syndr depr
\end{tabular}} & \multicolumn{2}{|l|}{$\begin{array}{l}\text { Linear Regr }{ }^{4} \\
\text { GDS score as a } \\
\text { continuous function }\end{array}$} \\
\hline & $O R(C I)$ & $p$ & $O R(C I)$ & $p$ & $O R(C I)$ & $p$ & Unstandardized B (CI) & $p$ \\
\hline \multicolumn{9}{|l|}{ Sociodemographic Factors } \\
\hline \multicolumn{8}{|l|}{ Declining physical functioning } & $<0.001$ \\
\hline Usual activities (EQ-5D), some or severe problems & & $\mathrm{ns}$ & & ns & $3.50(1.85-6.61)$ & $<0.001$ & $1.02(0.60-1.43)$ & $<0.001$ \\
\hline Self-Care (EQ-5D), some or severe problems & $5.49(2.08-14.47)$ & 0.001 & & ns & & & & \\
\hline \multicolumn{9}{|l|}{ Neuropsychiatric factors } \\
\hline History of Affective psychiatric disorder & $3.46(1.27-9.43)$ & 0.015 & & ns & & ns & & ns \\
\hline $\begin{array}{l}\text { Actual Anxiety/Depression (EQ-5D), moderate or } \\
\text { extreme }\end{array}$ & & $\mathrm{ns}$ & $6.88(1.47-32.23)$ & 0.014 & & ns & & ns \\
\hline Use of Tranquilizing medication & $3.88(1.09-13.80)$ & 0.037 & & $\mathrm{~ns}$ & $3.62(1.45-9.00)$ & 0.006 & $1.05(0.45-1.66)$ & 0.001 \\
\hline History of Stroke & $2.89(1.17-7.13)$ & 0.022 & & $\mathrm{~ns}$ & $2.44(1.14-5.21)$ & 0.021 & $0.90(0.42-1.39)$ & $<0.001$ \\
\hline \multicolumn{9}{|l|}{ Existential factors } \\
\hline Worries about the future, sometimes or often & & $\mathrm{ns}$ & & ns & $2.33(1.27-4.27)$ & 0.006 & $0.60(0.26-0.94)$ & 0.001 \\
\hline Lower self-perceived health (EQ VAS) & $6.91(3.54-13.48)$ & $<0.001$ & & ns & $5.09(2.69-9.61)$ & $<0.001$ & $0.79(0.43-1.15)$ & $<0.001$ \\
\hline Life not meaningful & $5.86(2.40-14.33)$ & $<0.001$ & $3.77(1.29-10.99)$ & 0.015 & $5.85(2.87-11.88)$ & $<0.001$ & $1.55(1.10-1.99)$ & $<0.001$ \\
\hline
\end{tabular}

${ }^{1}$ Nagelkerke $R^{2}=0.464$

${ }^{2}$ Nagelkerke $R^{2}=0.246$

${ }^{3}$ Nagelkerke Pseudo- $R^{2}=0.506$. Test of parallell lines: $p=0,842$, indicating an ordinal logistic model is fair to the data.

${ }^{4}$ Adjusted $R^{2}=0.478$ 


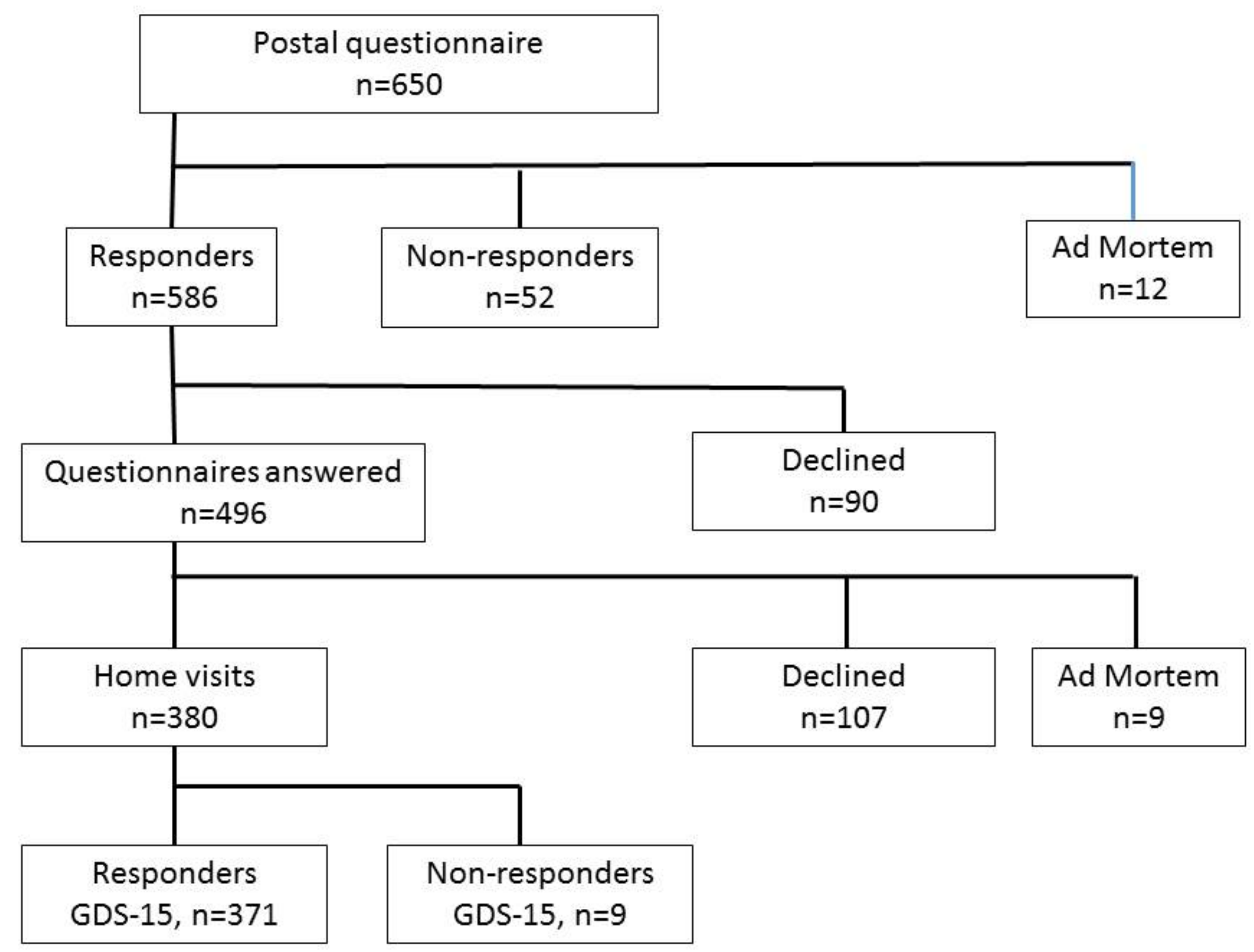

Figure 1. Derivation of the analytical samples from the ELSA-85 study. 


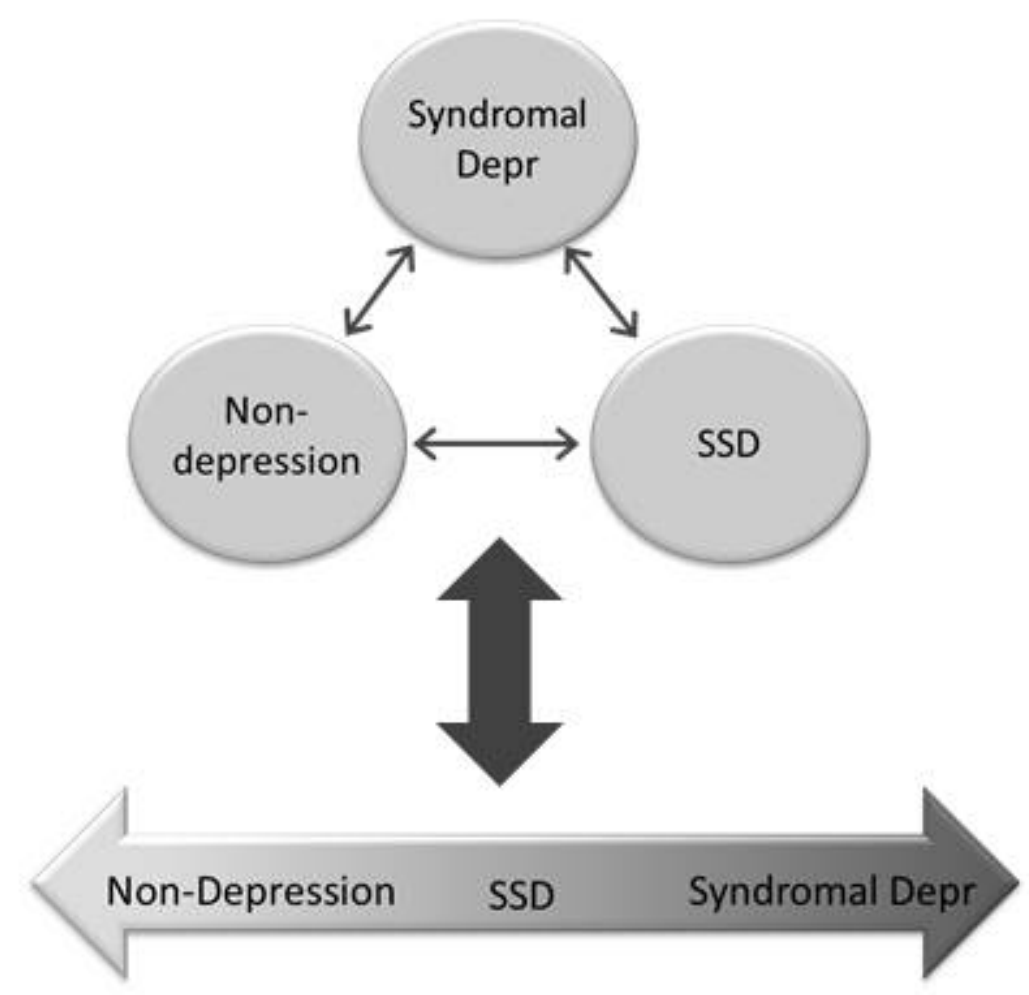

Figure 2. Conceptual description of the two perspectives on depressiveness, i.e. dimensional perspective (below) and Categorical perspective (above). In the dimensional perspective, depressiveness is regarded as a continuous mood condition from nondepressiveness to syndromal depression. This is contrasting to the categorical perspective, where non-depression, subsyndromal depression and syndromal depression are considered as distinctly different states of mood/depressiveness. 